\title{
choer
}

\section{Considerações sobre educação, arte e política: experiências, alternativas e resistências}

\section{Edite Colares Oliveira Marques}

PhD em Belas Artes pela Universidade do Porto

Doutora em Educação pela Universidade Federal do Ceará - UFC

Professora na Universidade Estadual do Ceará - UECE

edite.marques@uece.br

\section{Resumo}

\begin{abstract}
Este artigo aborda as interfaces entre educação, arte e política, voltando-se ao percurso histórico da educação artística brasileira com base na legislação e na experiência docente em Arte-Educação na Universidade Estadual do Ceará (UECE). Constata-se, a partir da análise da legislação, que a recente criação de uma Base Nacional Curricular Comum (BNCC) gera, na escola, uma redução do espaço do ensino de arte no Brasil. Lançamos luz sobre a formatividade da arte na vida humana; em seguida, articulamos a legislação à prática escolar de arte; e, por fim, exemplificamos os caminhos alternativos encontrados pela população como mecanismos de garantia de acesso à arte e à cultura no Brasil. O caráter utópico da arte é o que a faz ter sido sempre expressão dos anseios por um devir construído em busca de uma sociedade mais justa, onde a socialização dos bens imateriais da humanidade seja garantida pela escola.
\end{abstract}

Palavras-chave arte; educação; política; resistência. 


\title{
Considerations on education, art, and politics: experiences, alternatives, and resistance
}

\begin{abstract}
This article addresses the interfaces between education, art, and politics, focusing on the history of Brazilian art education based on legislation and teaching experience in Art-Education at the Ceará State University (Universidade Estadual do Ceará - UECE). It is found, having the analysis of legislation as a basis, that the recent creation of a Common National Curriculum Base (Base Nacional Curricular Comum - BNCC) generates, within the school, a reduced space for art teaching in Brazil. We shed some light on art formativity in human life; then, we interconnect legislation to school art practice; and, finally, we exemplify the alternative ways found by the population as mechanisms to guarantee access to art and culture in Brazil. The utopian nature of art is what makes it have always been an expression of longings for a future built to seek a fairer society, where socialization of the immaterial heritage of humanity is guaranteed by the school.
\end{abstract}

Key words art; education; politics; resistance.

\section{Consideraciones sobre educación, arte y política: experiencias, alternativas y resistencias}

\section{Resumen}

Este artículo aborda las interfaces entre educación, arte y política, volviéndose al recorrido histórico de la educación artística brasileña con base en la legislación y en la experiencia docente en Arte-Educación en la Universidad del Estado de Ceará (Universidade Estadual do Ceará - UECE). Se constata, teniendo como base el análisis de la legislación, que la reciente creación de una Base Nacional Curricular Común (Base Nacional Curricular Comum - BNCC) genera, dentro de la escuela, una reducción del espacio de enseñanza de arte en Brasil. Arrojamos algo de luz sobre la formatividad del arte en la vida humana; a continuación, articulamos la legislación a la práctica escolar de arte; y, por fin, ejemplificamos los caminos alternativos encontrados por la población como mecanismos de garantía de acceso al arte y a la cultura en Brasil. El carácter utópico del arte es lo que la hace haber sido siempre una expresión de los anhelos por un devenir construido en busca de una sociedad más justa, donde la socialización de los bienes inmateriales de la humanidad sea garantizada por la escuela.

Palabras clave arte; educación; política; resistencia.

\section{Considérations sur éducation, art et politique: expériences, alternatives et résistances}

\section{Résumé}

Cet article traite des interfaces entre éducation, art et politique et aborde le cours historique de l'éducation artistique brésilien basée sur la législation et l'expérience pédagogique en Art-Éducation à l'Université d'État de Ceará (Universidade Estadual do Ceará - UECE). Sur la base de l’analyse de la législation, il a été constaté que la création récente d'une Base National Commune du Programme (Base Nacional Curricular Comum - BNCC) génère, au sein de l'école, un espace réduit pour l'enseignement de l'art au Brésil. Nous avons mis en lumière le caractère formatif de l'art dans la vie humaine; ensuite, nous articulons la législation à la pratique artistique à l'école; et, enfin, nous illustrons les voies alternatives trouvées par la population en tant que mécanismes garantissant l'accès à l'art et à la culture au Brésil. Le caractère utopique de l'art est ce qui fait qu'il a toujours été l'expression des aspirations d'un devenir construit à la recherche d'une société plus juste, où la socialisation du patrimoine immatériel de l'humanité est garantie par l'école.

Mots-clés art; éducation; politique; résistance. 


\section{Introdução}

Iniciamos esta reflexão movidos pela proposta de abordar as interfaces entre educação, arte e política, identificando caminhos possíveis a partir de experiências, alternativas e resistências e voltando-nos ao percurso da educação artística brasileira nas últimas décadas. Constatamos que um conjunto de medidas na área não nos coloca em um lugar muito confortável, se pusermo-nos a olhar o ensino de arte no Brasil. De saída, já nos deparamos com um processo histórico de negação dos povos originários e de suas manifestações, que não foram vistas como arte ou cultura; portanto, o padrão colonizador é o que foi imposto como único válido.

Um povo que sempre foi vitimado pela ocupação de suas terras e por sua negação não encontra condições ideais para as expressões artísticas ou para a aprendizagem de suas linguagens; não obstante, a característica principal, que nos marca é a criatividade para encontrar alternativas e manter viva a centelha que acende uma fogueira de cores e formas que representam nosso modo de ser e estar no universo. A dança ritual, as músicas de batuques, as infinitas representações, que explodem em visualidades das mais diversas materializam de modo inequívoco a arte, que sempre foi instrumento de resistência ao colonialismo - assumido pelo sistema educacional brasileiro. Apesar da negação da identidade originária, ela compõe um cenário artístico-cultural na sociedade e na educação brasileira, no qual o discurso oficial entra em debate com uma arte genuína, experimental e marginal e uma resistência ao monoculturalismo que aqui se quis implantar.

Hoje, o que temos como legislação no campo do ensino de arte no Brasil é fruto de lutas históricas que, em um crescente, foram alcançando vitórias desde a inclusão da arte como atividade, ainda nos anos 1970, até a obrigatoriedade da área no currículo da educação básica, enquanto componente curricular, o que alcançamos com a Lei n. 9.394 (Lei de Diretrizes e Bases da Educação [LDB], 1996), para, por fim, encontrarmos na nova lei educacional brasileira, a Base Nacional Curricular Comum (BNCC,2017.), um retorno de sua presença como uma área do componente curricular Linguagem - uma verdadeira regressão. Pois, mesmo ainda estando longe de chegar a um patamar minimamente desejável para um ensino significativo das linguagens artísticas na escola, enfrentamos recuos e ataques do grupo político e econômico que governa o Brasil, o que nos fez perder o espaço da arte na implantação da BNCC (n.d.) recentemente. O fato é que, aliado aos interesses de uma elite econômica multinacional, o sistema de ensino submete o povo brasileiro a se manter em uma aprendizagem ligada a saberes necessários ao mundo do trabalho e, para tanto, a arte se mostra desnecessária.

O problema que aqui apresentamos é o entendimento dos elos entre arte, educação e política, descortinando alternativas, resistências e experiências que foram forjadas, com o propósito de perceber além das aparências e do discurso oficial sobre o lugar da 
educação estética e da formação cultural e artística no Brasil. E, finalmente, a questão de saber identificar as conexões entre o desenvolvimento histórico do ensino/aprendizagem da arte e a ideia de uma finalidade objetiva presente na legislação pertinente à área quanto à educação escolar, ou seja, fazer pensar o que significa essa minimização da área de artes no currículo brasileiro.

Traçamos, então, uma trajetória na qual: a) primeiro, lançamos luz sobre a formatividade da arte na vida humana; b) em seguida, articulamos a legislação à prática escolar de arte; e c) finalmente, buscamos os caminhos alternativos encontrados pela população como mecanismos de garantia do acesso à arte e à cultura no Brasil. Tal procedimento de análise da realidade do desenvolvimento cultural e artístico enquanto ensino escolar de arte proporciona uma visão alargada das vivências cotidianas, em busca de expressão e educação artística.

\section{A formatividade da arte}

A quais necessidades humanas a arte atende que de nenhuma outra maneira o ser humano o faria? Para quê arte em um mundo tão cheio de apelos e atividades?

Desde os primórdios do homem na postura ereta, iniciou-se uma pintura rupestre que o faz não só representar o vivido, mas criar sistemas de contagem, indicar movimento e, acredita-se, transcender em uma ligação cósmica com danças rituais, mais tarde colocando-se nesse universo e intervindo no meio físico, fazendo estruturas circulares, com pedras monolíticas gigantescas, e inventando celebrações que fazem pensar que sentidos, emoções, experiências de expressão e arte formam o sujeito, em seu processo de humanização. A arte intervém, desde sempre, no modo do ser humano se colocar como presença no mundo, ou seja, ao constituir uma expressão artística, em qualquer de suas linguagens, a pessoa também vai formando-se e constituindo-se como sujeito de sua história, integrado à história e às condições reais de sua existência - situadas no espaço e no tempo.

Partindo do princípio de formatividade da arte, encontramos um sujeito historicamente situado - e faz toda a diferença nascer no Brasil ou na Alemanha, por exemplo. Não que Richard Wagner seja maior que Heitor Villa Lobos, mas porque o acesso à música em ambiente escolar, nesses países, é diametralmente oposto, mas os talentos existem e, de modos distintos, todos nós nos expressamos por música, primeiro espontaneamente, potencial que pode ser desenvolvido ou não. As criatividades são reais, mas, nos casos em que são reprimidas ou não incentivadas, deixando de oferecer condições ao desenvolvimento dessas disposições, reprime-se uma expectativa, não permitindo o pleno desenvolvimento das condições humanas de criação e de livre expressão pelas artes. 
Frisamos a distinção entre Brasil e Alemanha para exemplificar que, nesses sistemas de ensino, a atenção dada à música, por exemplo, é oposta - não pela qualidade criativa dos que ali estão, mas pelas condições de aprendizagem da linguagem musical encontrada na escola básica pelos mais jovens. Assim, ao terminar o ensino básico, o estudante alemão conhece a escrita musical e consegue fazer leituras simples de partituras, com o auxílio de instrumentos melódicos, enquanto o brasileiro não é alfabetizado na música ocidental e não toca de maneira básica nenhum instrumento. Aqui, somente há poucos anos é que se conseguiu instituir o ensino obrigatório de música na escola, mas já se recuou, na legislação mais recente, na qual toda a área de arte foi reduzida à condição de parte do componente curricular Linguagem. Ou seja, o status de obrigatoriedade, há pouco alcançado, já deixou de existir na BNCC (2017). Isso é muito desalentador, pois não nos encontramos sequer nos patamares mínimos de aprendizagem da música para já nem mencioná-la como campo específico do conhecimento e, portanto, como um componente curricular específico na BNCC (2017) para essa grande formadora do saber, propiciadora de criações e de entendimento do mundo, fenômeno particular da comunicação humana, indispensável na aprendizagem escolar: a arte.

O caráter formativo da arte, sua fonte de comunicação, suas variadas formas de expressão humana, potencializadoras de descobertas e de aprendizagens, dentre outras categorias de análise que circundam a necessidade humana das artes, constituem o foco do primeiro momento deste artigo. A matéria da arte, tanto para Eco (2013, p. 17) como para nós, é sua formatividade, categoria primordial na escola e no desenvolvimento humano:

\footnotetext{
[...] segundo a estética da formatividade, o artista, ao formar, inventa efetivamente leis e ritmos totalmente novos, mas essa novidade não surge do nada, e sim nasce exatamente como livre resolução de um complexo de sugestões que a tradição cultural e o mundo físico propuseram ao artista sob forma inicial de resistência e passividade codificada.
}

No ambiente escolar, a arte deve ser reconhecida tanto como forma de comunicação, interpretação, expressão quanto como fonte de muitas descobertas. Então, fica a pergunta:

- Porque se deve dar atenção ao componente Arte na escola, de modo específico e com distinção?

Aqui, tomamos a música para exemplo, mas poderia ser outra linguagem, como o teatro ou a dança; em todas essas expressões, um dos primeiros elementos a destacar seria a criatividade envolvida. Ao lidar com os elementos constitutivos da linguagem em questão, como o ritmo, a melodia e os timbres na música, a pessoa precisa articulá-los de maneira harmoniosa, criando beleza em uma peça nos mais diversos gêneros musicais. Tal 
processo é único, mas sua singularidade depende de um repertório mínimo, para permitir sua articulação, criando algo próprio. Balbuciando os primeiros sons olvidos no colo, para dormir, a criança já confere uma interpretação a eles e representa as situações de ninar. É comum crianças pequenas cantarolarem canções inventadas, ou seja, com o suporte dos elementos constitutivos das linguagens artísticas que conhecem, as crianças iniciam um processo criativo que precisa ser enriquecido pela família e, principalmente, pela escola.

Sem dúvida, o elemento criatividade não compõe somente a arte. O homem a desenvolve de muitas maneiras e, sem dúvida, responde a muitas necessidades cotidianas com criatividade, no entanto, da arte temos sua indissociabilidade, pois o contato com a arte já exige uma reação criativa mesmo nos momentos de apreciação. Cada expectador ressignifica a imagem, a música ou qualquer expressão artística com a qual se depare. A imaginação e a capacidade de representação são elementos fortalecidos durante o contato com a arte, pois, a todo momento, geram-se formas, cores, sons e movimentos, que alimentam a imaginação, substrato da criatividade. Esse modo de interagir com a obra vai evoluindo na medida em que se tem maior número de oportunidades de contato, razão pela qual o acesso à arte na escola é tão indispensável ao estudante.

Diante de uma obra de arte, a interpretação do espectador é o que conta. Para Eco (2013, p. 60), "uma experiência interpretativa plena irá coincidir, ademais, com aquela experiência produtiva em que a obra em si representava, mas isso se dará segundo uma perspectiva pessoal”. Desse modo, a experiência pessoal completa o sentido da arte, a interpretação atribui-Ihe sentido. Segundo Eco (2013, p. 61), "essa perspectiva pessoal é, ela mesma, implicitamente, um juízo, mas tão rico e articulado que os elementos de subjetividade que o compõem, em vez de comprometer sua validade, fundamentam sua eficácia e novidade". Portanto, o contato com a arte é um ato criativo por si. Apresentar os estudantes às artes, em variados formatos, em momentos frequentes e com uma abordagem diversificada é uma obrigação da escola, mas, em um país onde nem a escola básica é uma garantia, precisamos realizar muito, ainda, para termos o mínimo exigido por uma educação também do sensível, uma educação estética.

Os atos de fruir, conhecer e experimentar arte se tornaram uma tríade sobre a qual se sustentava a necessidade e a estrutura de suporte ao ensino das artes na escola. Esse triplo fazer nas artes (o fruir, o conhecer e o experimentar), já nos anos 1960, é apregoado por Herbert Head (1983), com quem comungo da opinião de que esse suporte é muito capaz de dar sustentação a uma formação humana mais criativa e consciente dos desafios que se precisa enfrentar na constituição de uma disciplina de arte na educação. Ana Mae, na década de 1990, traz esse pensamento ao Brasil e, junto com os organizadores dos Parâmetros Curriculares Nacionais ( $\mathrm{PCN}$ ), institui a proposta triangular que orienta os PCN de 1998, publicados pelo Ministério da Educação (MEC), sobre o ensino fundamental de arte no Brasil. 
É o mesmo caráter formativo que aqui retomamos para dizer que não devemos retroceder, mas avançar nas escolas brasileiras quanto ao valioso papel educativo da arte, por uma tríplice possibilidade de fazer esse modo humano de atribuir sentido à existência. Seja na fruição de obras e vivências artísticas, seja na descoberta dos contextos sociais de seus idealizadores ou, ainda, experimentando a invenção artística, em todos os casos esse contato será uma oportunidade de descobertas e criações, colocando o estudante em uma situação propositiva, ativa, instigante que devemos proporcionar no contexto da escola.

\section{Metodologia e discussão}

\section{Da análise da legislação à prática escolar de arte}

Procedemos a análise documental. Nela nos aprofundamos, em uma retrospectiva histórica, com base na evolução da legislação pertinente ao campo da arte no âmbito do ensino regular, como fonte de dados sobre os quais se pode identificar avanços e retrocessos, procurando desvendar causas e efeitos do modelo educacional em vigor.

Retrocedendo na história educacional brasileira, pode-se identificar uma evolução na legislação da educação, que vinha, nas últimas três décadas, desde a Constituição da República Federativa do Brasil (CF, 1988), intervindo diretamente nas práticas de ensino de arte na escola de modo crescente e propositiva. Vejamos como:

- CF (1988) - "Art. 210. Serão fixados conteúdos mínimos para o ensino fundamental, de maneira a assegurar formação básica comum e respeito aos valores culturais e artísticos, nacionais e regionais".

- LDB (1996) - "Art. 26. Os currículos da educação infantil, do ensino fundamental e do ensino médio devem ter base nacional comum, a ser complementada, em cada sistema de ensino e em cada estabelecimento escolar, por uma parte diversificada, exigida pelas características regionais e locais da sociedade, da cultura, da economia e dos educandos".

- Lei n. 11.645 (2008) - dispõe acerca da obrigatoriedade da inclusão da temática "História e Cultura Afro-Brasileira e Indígena" nos currículos oficiais, nos termos do art. 26-A da LDB (1996):

\footnotetext{
§ 10 O conteúdo programático a que se refere este artigo incluirá diversos aspectos da história e da cultura que caracterizam a formação da população brasileira, a partir desses dois grupos étnicos, tais como o estudo da história da África e dos africanos, a luta dos negros e dos povos indígenas no Brasil, a cultura negra e indígena brasileira e o negro e o índio na formação da sociedade nacional, resgatando as suas contribuições nas áreas social, econômica e política, pertinentes à história do Brasil.
} 
§ 20 Os conteúdos referentes à história e cultura afro-brasileira e dos povos indígenas brasileiros serão ministrados no âmbito de todo o currículo escolar, em especial nas áreas de educação artística e de literatura e história brasileiras.

Lembramos, ainda, que a legislação específica mais recente sobre a arte, a Lei $\mathrm{n}$. 13.278 (2016), reforça a ideia anterior de que o ensino de arte deve ocorrer nas 4 linguagens (Colares, 2018).

Também é oportuno recordar que a linguagem musical recebeu destaque e o presidente Lula sancionou a Lei n. 11.769 (2008), que estabeleceu a obrigatoriedade para a área de educação musical no país. A aprovação dessa lei foi, sem dúvida, uma grande conquista para todos que militam na área e para seus maiores beneficiários - a categoria estudantil.

Os referidos documentos estabelecem um conjunto de normatizações que precisavam ter sido postas em prática, mas não foram, como tantas outras leis do ensino e da educação, e acabaram por ser substituídas sem nunca ser implementadas.

Acrescendo-se a esses documentos, aos quais já nos referimos, também destacamos outra legislação: a que determina a cultura negra e indígena, que nas últimas décadas vinha fundando um olhar mais equilibrado sobre as matrizes étnicas e culturais brasileiras, em contexto educativo.

Propomos embasar a discussão sobre arte, política e educação - no ensino de artes na educação básica brasileira - nesses recentes diplomas legais nacionais, que a BNCC (n.d.), no processo de normatização do ensino e aprendizagem na educação básica, acaba por desconsiderar, apoiado pelo governo que ora assume o comando e o destino da nação. Vejamos a Lei n. 12.287 (2010, grifo nosso) - o § 2ํdo art. 26 da LDB (1996), que já estabelecia o ensino da arte como componente curricular obrigatório nos diversos níveis da educação básica, passou a destacar, também, a presença das expressões regionais:

§ $2^{\circ} \mathrm{O}$ ensino da arte, especialmente em suas expressões regionais, constituirá componente curricular obrigatório nos diversos níveis da Educação Básica, de forma a promover o desenvolvimento cultural dos alunos.

A LDB (1996) já obrigava o estudo da cultura afro-brasileira e indígena para compor com a de origem europeia, única até então, sistematizada no currículo escolar brasileiro. A Lei n. 11.645 (2008) deu a seguinte redação ao art. 26-A da LDB (1996): 
§ 10 O conteúdo programático a que se refere este artigo incluirá diversos aspectos da história e da cultura que caracterizam a formação da população brasileira, a partir desses dois grupos étnicos, tais como o estudo da história da África e dos africanos, a luta dos negros e dos povos indígenas no Brasil, a cultura negra e indígena brasileira e o negro e o índio na formação da sociedade nacional, resgatando as suas contribuições nas áreas social, econômica e política, pertinentes à história do Brasil. $\S 20$ Os conteúdos referentes à história e cultura afro-brasileira e dos povos indígenas brasileiros serão ministrados no âmbito de todo o currículo escolar, em especial nas áreas de educação artística e de literatura e história brasileira.

Vale indagar os motivos pelos quais as orientações contidas nos diplomas supracitados são desprezadas na BNCC (20017), sem aprofundar a discussão com os professores da escola básica e/ou dos sistemas de ensino. Desse modo, a abordagem aqui exposta destaca, em especial, as duas temáticas respaldadas na própria legislação brasileira: a diversidade cultural brasileira e o ensino de arte, tanto na formação de educadores quanto sua inserção na sala de aula da escola básica e, por outro lado, almeja proporcionar um olhar mais aguçado sobre a BNCC (2017), em sua "não componente" curricular Artes.

Nossa fala tenta envolver professores universitários e da educação básica, bem como estudantes de graduação e pós-graduação, na reflexão, com base em relatos de experiências, visitas a espaços de arte, e práticas de formação de professores, sobre a visão da arte que temos e a distância que dela queremos, a que deve servir de base cultural comum a qualquer criança, bem como sobre as culturas que aqui conviveram e convivem, ou seja, o povo do interior e da cidade, do sertão e do litoral, o negro, o indígena e o branco.

Consideramos que o "conhece-te a ti mesmo" deve ser o ponto de partida para toda a educação. O homem, a mulher, a criança e o jovem, esses sujeitos reais, ao se situarem na vida local, projetando-se na visão do outro, devem ir, mais e mais, conseguindo expressar-se e comunicar-se também por suas artes, nas escolas, projetando-se para um amplo espaço social - objetivo de uma educação escolar libertadora. Concordamos com Rancière (2015, p. 87), para quem “o princípio da veracidade está no coração da experiência emancipadora”. E nada é mais libertador do que a arte, pois não prescinde da verdade do eu em consonância com o todo.

Como vemos, as políticas públicas educacionais reorientaram a prática pedagógica em artes para uma visão da diversidade étnico-cultural, em uma abordagem interdisciplinar que nos obrigou a recolocar a problemática da educação em artes, desde os anos 1990. O diálogo entre matrizes étnicas fundadoras da sociedade brasileira viria a contribuir efetivamente para fomentar as discussões acerca dos temas propostos, desenvolvendo um conhecimento da arte e da cultura de forma diversificada, multicultural e inclusiva. Assim decorreria uma reverberação nas comunidades escolares, algo que, nos parece, não é o objetivo da classe detentora do poder. 
Todas essas legislações traziam implicações para os sistemas de ensino e para os profissionais da educação, com pautas importantes direcionadas a uma ampla discussão em torno de como a arte e a cultura brasileira vêm sendo ensinadas na escola básica brasileira e de como isso deveria ocorrer de fato.

O modelo social que estava desenhando-se, com o governo do Partido dos Trabalhadores (PT), apesar de não ser nada revolucionário, vinha dando pequenos passos no sentido da valorização e do reconhecimento da cultura afro e indígena, pelo menos do ponto de vista legal, no âmbito da educação escolar. Podíamos ver na legislação aludida um projeto que não atendia, exatamente, aos interesses da classe empresarial, bem representada nas casas legislativas.

Então, em 6 de abril de 2017, após ser retirada do Conselho Nacional de Educação (CNE) toda a oposição e metade da representação da sociedade civil, em seguida ao golpe político que retirou a Presidente Dilma Rousseff do Governo Federal, o CNE recebeu do MEC, em cumprimento a orientações de ordem legal e normativa sobre a matéria, o documento da BNCC (2017), com proposta pactuada em todas as Unidades da Federação, estipulando-se ali no texto da Lei direitos e objetivos de aprendizagem e desenvolvimento, para os alunos da Educação Básica, nas etapas da Educação Infantil e do Ensino Fundamental.

Em seu art. 1ํ, a Resolução N. 2 do Conselho Nacional de Educação e seu anexo, que instituem a BNCC (2017) como documento de caráter normativo, define o conjunto orgânico e progressivo de aprendizagens essenciais como direito das crianças, jovens e adultos no âmbito da educação básica escolar, e orientam sua implantação pelos sistemas de ensino das diferentes instâncias federativas, bem como pelas instituições ou redes escolares, como se lê a seguir:

\footnotetext{
Art. 2ำ As aprendizagens essenciais são definidas como conhecimentos, habilidades, atitudes, valores e a capacidade de os mobilizar, articular e integrar, expressando-se em competências. Art. 3ํ№ âmbito da BNCC, competência é definida como a mobilização de conhecimentos (conceitos e procedimentos), habilidades (práticas cognitivas e socioemocionais), atitudes e valores, para resolver demandas complexas da vida cotidiana, do pleno exercício da cidadania e do mundo do trabalho. Art. 4- A BNCC, em atendimento à LDB e ao Plano Nacional de Educação (PNE), aplica-se à Educação Básica, e fundamenta-se nas seguintes competências gerais, expressão dos direitos e objetivos de aprendizagem e desenvolvimento, a serem desenvolvidas pelos estudantes: 1. Valorizar e utilizar os conhecimentos historicamente construídos sobre o mundo físico, social, cultural e digital para entender e explicar a realidade, continuar aprendendo e colaborar para a construção de uma sociedade justa, democrática e inclusiva. (2017, p.4)
} 
É bem sintomático do retrocesso que vivemos que, nos 4 primeiros artigos da BNCC (2017), a competência sempre tenha sido destacada para justificar o desempenho para o mundo do trabalho como objetivo do desenvolvimento do estudante e não como parte da educação integral do aprendiz. Não. O ponto de partida já é a competência, o que não deixa dúvida sobre a atenção ao sujeito que se prepara na escola para esta sociedade. Quem se quer formar?

No próprio texto da lei, no § 1º do art. 36 da LDB (1996), esclarece-se que "a expressão 'competências e habilidades' deve ser considerada como equivalente à expressão 'direitos e objetivos de aprendizagem' presente na Lei do Plano Nacional de Educação (PNE)”.

O ideal elucidado na BNCC (2017) deixa claro que o interesse defendido é francamente perceptível: a busca, antes de mais nada, da preparação para o mundo do trabalho e não da formação de um sujeito consciente de si e à procura de uma educação emancipadora e de uma sociedade mais justa, redistributiva das dívidas sociais, na qual se encontre uma divisão mais justa das riquezas. O mundo da competência e não o da busca da felicidade, do equilíbrio e da criatividade. Um tipo muito claro de cidadão é o objetivo de nossa mais recente legislação educacional: um cidadão pacato, conformado com uma vida voltada ao trabalho mecânico.

A arte é sempre a primeira a ser atacada nas sociedades onde mais se exploram os cidadãos, por interesses espúrios de uma classe empresarial. Quanto mais se explora, mais se almeja um alienado, preso às condições estabelecidas, um reprodutor do já pronto, um realizador de ordens, um "burro de carga", um trabalhador obediente. Nesse caso, o mundo da arte é perigoso, pois o sujeito se torna mais radical, curioso, criativo, questionador. Não interessa ao sistema em vigor.

Ressaltamos, na BNCC (2017), a redução da importância da arte no conjunto das disciplinas ou áreas de conhecimento, pois ela sequer figura no conjunto das disciplinas, passando a ser parte da componente Linguagem. Tal recolhimento tem significado muito profundo de uma educação que traz como princípio não só o mundo do trabalho, mas uma concepção de educação enquanto reprodução de conhecimentos e não de sua construção em uma atitude propositiva, atuante.

Removê-la de sua centralidade, de seu caráter de componente curricular específico, representa colocá-la em último plano, porque, como bem sabemos, esse é um conteúdo escolar já pouco desenvolvido, uma verdadeira nulidade nas práticas escolares, mesmo que conste desde a LDB (1996) como um componente obrigatório no hall das disciplinas. Ou seja, a obrigatoriedade da arte na escola se regulamentou desde os anos 1990, atribuindoIhe status de disciplina e, ainda assim, o desenvolvimento das artes na escola se mostra bem incipiente, fato que podemos comprovar ao receber universitários de "Introdução à Arte-Educação" na Universidade Estadual do Ceará (UECE). 
Confirmada sua relevância nos Parâmetros Curriculares do Ensino Fundamental, que destinaram a ela a mesma atenção que às demais disciplinas, desde o final da década de 1990 (há 20 anos), que vem evoluindo de maneira lenta, por meio de mudanças quase imperceptíveis. Isso pode ser verificado a partir do resultado da aprendizagem escolar de arte, quando observamos os recém-formados do Ensino Médio que ingressam na UECE. Na verdade, precisávamos aprofundar as ações já iniciadas, que vinham ampliando o campo das artes na escola em vez de reduzi-lo, como fez a BNCC (2017).

É uma afronta ter no art. 14 da BNCC (2017) que:

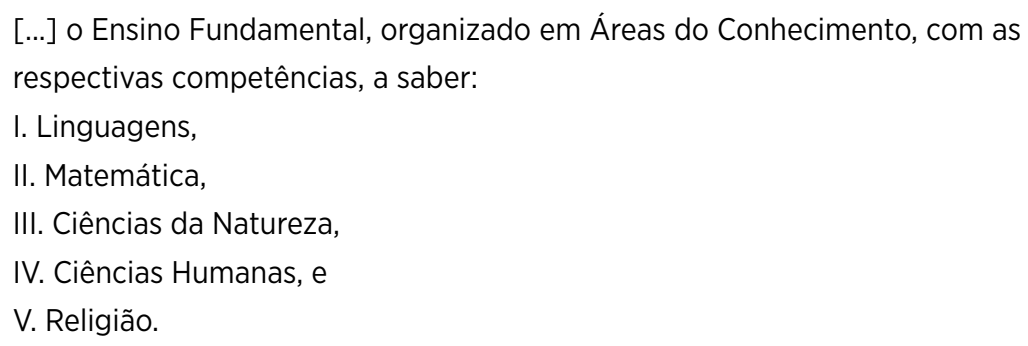

É no mínimo inócuo não se encontrar artes como área específica do conhecimento, não permanecendo como disciplina independente na recente BNCC (2017). É no mínimo contraditório, em um estado laico, termos Religião como conteúdo escolar obrigatório, pois, ao pensar o público escolar oriundo da classe trabalhadora, vemos que às expressões artísticas mais eruditas, por exemplo, essas crianças só terão acesso na escola, pois tantas vezes o lugar de acesso a padrões culturais mais complexos ou elaborados só é possível na escola, enquanto a Religião se aprende, também, na Igreja e na orientação religiosa por parte das famílias.

\section{Resultados: alternativas e possibilidades}

Com base em experiências que comprovam a pertinência da arte na formação de crianças e jovens, entendemos que alternativas devem ser procuradas por educadores e educandos. Parece-nos ser impossível submetermo-nos à redução da arte na BNCC (2017). É um absurdo o que se almeja ao negar o acesso à arte na escola, de modo ainda mais gritante atualmente. Omitir artes por trás do componente Linguagem dificulta ainda mais as possibilidades de aprendizagem significativa delas.

Não se questiona que artes sejam linguagens, apenas afirmamos que elas constituem área específica do conhecimento, com elementos constitutivos próprios, que não se limitam ao componente Linguagem, pois o ser humano, ao fazer artes, antes de comunicar-se, absorve e reelabora suas emoções, ressignifica, rumina, vive de modo refletido, sentido... 
Então, do ponto de vista educativo, a função primeira da arte é contribuir para a educação emocional, fazendo o estudante viver as experiências que as emoções e os sentimentos propõem, colocando o sujeito em equilíbrio e harmonia profunda, conhecendo o outro e conhecendo-se.

Remetemo-nos ao papel de autoconhecimento que a arte proporciona e que faz desses saberes artísticos, antes mesmo de uma criativa forma de expressão e de comunicação, um rico suporte para experimentação poética de sentimentos, ideias e emoções, fazendo o indivíduo elaborar suas emoções, tendo domínio sobre elas e facilitando um maior equilíbrio pessoal e interpessoal.

A vivência da arte no ambiente escolar gera um clima descontraído, vívido, alegre. Já dizia a sabedoria popular que "quem canta seus males espanta"; diríamos nós que quem canta, dança, pinta e representa, seus males espanta. Porque mesmo ao experimentar sentimentos de perda e de dor, a arte se faz com beleza e harmonia, razão pela qual se amortece a dor, dando contornos poéticos e acomodando com maior equilíbrio emocional as situações cotidianas.

O fazer artístico na escola, exatamente pelo ambiente colaborativo que favorece, é um importante conteúdo, se assim o podemos chamar. O certo é que trabalhando as emoções de crianças e educadores no âmbito escolar, criam-se as condições de uma relação escolar instigante e interativa entre estudantes e professores. Pelo prazer da criação, relativizam-se muitas tensões existentes na sala de aula. Portanto, há um trabalho mais sensível e que é anterior à linguagem.

Em última análise, o que aqui está em jogo é a condição anterior à linguagem que a arte apresenta, essa poiésis, que torna a vida e a escola um gosto, uma necessidade emocional, significativa e significante, rica em amadurecimento emocional, indispensável à educação de qualidade.

Muitas são as experiências exitosas na educação artística, dentro e fora da escola. Entretanto, porque na escola não se tem as condições necessárias à sua realização, os estudos mostram que fora da escola, em organizações não governamentais (ONGs), espaços culturais, escolas de artes e outras formas de organização civil, fluem muitas situações de ensino-aprendizagem nesse campo de saberes.

Inúmeras são as experiências desenvolvidas em Fortaleza-CE fora da escola regular de ensino, em escolas de artes, por exemplo. Citaremos uma, pois, com esse exemplo, representamos a gama de possibilidades educativas em artes que são desperdiçadas ano a ano pelo sistema de ensino. Na Escola de Dança e Integração Social para Criança e Adolescente (EDISCA), os alunos vivem uma educação em artes, com aulas de dança, balé clássico e, assim, ao lado dos estudos escolares, agregam desenvolvimento psicomotor, espaço-temporal e emocional, desenvoltura em público, dentre outras habilidades que favorecem a aprendizagem e a educação integral do estudante. Já há resultados muito 
positivas na formação desses aprendizes, pois, depois de anos de estudos, alguns desses jovens tomaram a dança como profissão e hoje são professores e bailarinos profissionais.

Citamos a EDISCA para comprovar a grande potencialidade que a arte representa na vida humana e como a escola perde ao não realizar trabalhos mais criativos, emocionantes, enriquecedores, pertinazes. Outro modelo de experiência que aqui vale ressaltar são os grupos tradicionais comunitários, como um que encontramos no Pirambu, que é animado pelo Mestre Zé Pio. Nele, pessoas da comunidade, indistintamente, crianças, jovens e até idosos, reúnem-se para vivenciar o Boi e fazem uma brincadeira que ganha sentido e desenvolve saberes das artes populares com pessoas das mais diferentes idades. A prática tradicional comunitária de cultura e arte, pensamos ser a forma mais orgânica de todas as experiências no âmbito do ensino das artes, uma vez que interage com a comunidade em um fazer inteiramente integrado ao conjunto de valores aos quais se está a dar significado. Cito o Boi do Mestre Zé Pio, pois ele tem tido uma inserção e uma representatividade na vida de crianças e jovens de uma comunidade que, mesmo sendo uma das mais violentas da cidade, consegue envolver muitas pessoas que ali aprendem música, dança, e realizam um auto folclórico que envolve todas as artes.

Outra iniciativa ocorrida em Fortaleza, que foi muito oportuna para o ensino de artes e que propiciou um desenvolvimento de talentos juvenis para as artes pelos 3 cantos da cidade foi a Rede Cuca de proteção social e oportunidades, formada por 3 Centros Urbanos de Cultura, Arte, Ciência e Esporte (CUCAs), mantidos pela Prefeitura de Fortaleza por meio da Coordenadoria Especial de Políticas Públicas de Juventude. Geridos pelo Instituto Cuca, os Cucas Barra, Mondubim e Jangurussu atendem, prioritariamente, jovens de 15 a 29 anos, oferecendo cursos, práticas, difusão cultural, formações e produções na área de comunicação e atividades que fortalecem o protagonismo juvenil e realizam a promoção e garantia de direitos à cultura e à arte. Além disso, a Rede Cuca também tem levado para a periferia de Fortaleza possibilidades e alternativas de fruição artística, por meio da realização de eventos, festivais, mostras, exposições e programações permanentes de shows, espetáculos e cinema. Nesses 3 bairros de Fortaleza, a ação tem criado zonas de desenvolvimento de formação de jovens nas artes que, hoje, repercutem de modo muito positivo e propositivo na cidade, pois alguns desses jovens formaram grupos ou destacam-se individualmente no cenário das artes na capital do Ceará.

\section{Considerações finais}

A intenção deste artigo é refletir, junto aos estudiosos de políticas públicas na área de arte, cultura e educação, situando-se historicamente com base na legislação mais recente e observando as atuais determinações legais, sobre o campo da arte na educação brasileira. É facilmente perceptível que tivemos um grande recuo, especialmente no contexto da escola, 
no que tange ao espaço e à valorização das artes, uma vez que ela foi reduzida, na mais recente legislação educacional, a BNCC (2017), à parte da linguagem e não se atende às necessidades humanas de desenvolvimento das artes entre crianças e jovens em contextos escolares, comunitários e/ou de outras maneiras, a não ser nas iniciativas pontuais como as que citamos, ao lembrar a EDISCA, os CUCAs e o Boi do Mestre Zé Pio.

É justamente na política, primeiro, e depois em um conjunto de iniciativas que se encontram os bloqueios e às possibilidades do ensino de artes, pois fora da escola encontramos mais experiências exitosas das artes do que dentro dela. Se, por um lado, as políticas públicas do ensino regular na área de artes são desanimadoras, haja vista o que já expomos anteriormente, sua quase insignificância para os autores da lei, que instituíram a BNCC (2017), por outro lado, sua vivência fora da escola dá demonstrações de ricas experiências, entre as quais as que citamos, que ilustram o argumento de que os bons resultados da aprendizagem artística são irrefutáveis. Insistimos, aqui, que, mesmo antes de ser linguagem, já há uma arte ancestral em gestos, afetos e brincadeiras, que levam aos primeiros contatos com a arte e a senti-la inteiramente, sem ainda ser linguagem, mas sendo parte primeira da vida em comunidades humanas desde os tempos mais remotos.

Portanto, alertamos para o fato da arte ser fonte de criatividade e de descoberta, também constituindo utopia e resistência cultural. Assim, o que encontramos nas diversas experiências de artes, ainda que fora da escola, é um meio de manter viva a chama ancestral de sentir-se parte da vida comunitária, das possibilidades humanas de expressão de modos de viver e sentir a realidade que nos cerca. Assim é que esses exemplos são demonstrações de busca de alternativas de garantia de acesso à arte, quando a escola não cumpre seu papel de difusora da cultura e de campo fértil de criações e descobertas. O caráter utópico da arte é o que a levou a sempre ter sido expressão dos anseios por um devir construído por atores sociais em busca de uma sociedade mais justa, onde a distribuição dos bens imateriais da humanidade seja garantida pela escola, transcendendo seu caráter de aparelho ideológico de Estado, em uma perspectiva de transformação social e de criatividade coletiva.

Precisamos, então, ainda no solo da escola, suscitar a resistência que a sociedade brasileira exige de seus cidadãos, sob pena de aprofundar retrocessos inaceitáveis, como a minimização da arte na escola. É indispensável que se mantenham, mesmo que na divisão do tempo da área de linguagem, as aulas de artes em todas as escolas. Também urge utilizar o tempo da parte diversificada, que soma $40 \%$ do tempo escolar em todos os níveis, para ampliar o tempo da arte na escola, com práticas como as de cultura popular, nas quais os saberes regionais sejam amplamente difundidos. Então, finalizamos acrescentando que a formação e a atuação artístico-cultural de professores e estudantes dentro da escola devem ser instrumentos de busca de expressão dos anseios da população, de crianças, jovens e educadores, por uma educação mais crítica e criativa. 


\section{Referências bibliográficas}

Base Nacional Curricular Comum. (2017). Educação é a base. Recuperado de http:// basenacionalcomum.mec.gov.br/images/BNCC_El_EF_110518_versaofinal_site.pdf Colares, Edite (2018). Educação inicial em artes: identidade, cultura popular e ludicidade. Arte e diversidade: Anais do 20 Congresso Intersaberes em Arte, Museu e Inclusão. João Pessoa, PB. Acesso em: https://www.even3.com.br/anais/iiciami/?fbclid=IwAR1-CYkfhp6Q2wOV4Lxynu2VvAJG8oi

RVxhKA GSXOOsHrOfa86ZhEUbxzE

Constituição da República Federativa do Brasil, de 5 de outubro de 1988. (1988). Brasília, DF.

Eco, U. (2013). A definição da arte. Rio de Janeiro, RJ: Record.

Head, H. (1983). Arte e alienação. Rio de Janeiro, RJ: Zahar.

Lei n. 9.394, de 20 de dezembro de 1996. (1996). Estabelece as diretrizes e bases da educação nacional. Brasília, DF.

Lei n. 11.645, de 10 março de 2008. (2008). Altera a Lei n. 9.394, de 20 de dezembro de 1996,

modificada pela Lei n. 10.639, de 9 de janeiro de 2003, que estabelece as diretrizes e bases da educação nacional, para incluir no currículo oficial da rede de ensino a obrigatoriedade da temática "História e Cultura Afro-Brasileira e Indígena”. Brasília, DF.

Lei n. 11.769, de 18 de agosto de 2008. (2008). Altera a Lei n. 9.394, de 20 de dezembro de 1996, Lei de Diretrizes e Bases da Educação, para dispor sobre a obrigatoriedade do ensino da música na educação básica. Brasília, DF.

Lei n. 12.287 de 13 de julho de 2010. (2010). Altera a Lei n. 9.394, de 20 de dezembro de 1996, que estabelece as diretrizes e bases da educação nacional, no tocante ao ensino da arte. Brasília, DF.

Lei n. 13.278, de 2 de maio de 2016. (2016). Altera a Lei n. 9.394, de 20 de dezembro de 1996, que fixa as diretrizes e bases da educação nacional, referente ao ensino da arte. Brasília, DF.

Rancière, J. (2015). O mestre ignorante. Cinco lições sobre emancipação intelectual. Belo Horionte, MG: Autêntica. 


\section{Para citar este artigo:}

Norma A - ABNT

COLARES, E. O. Considerações sobre educação, arte e política: experiências, alternativas e resistências. Conhecer: Debate entre o Público e o Privado, v. 9, n. 23, p. 124-140, 2019.

\section{Norma B - APA}

Colares, E. O. (2019). Considerações sobre educação, arte e política: experiências, alternativas e resistências. Conhecer: Debate entre o Público e o Privado, 9(23), 124-140.

\section{Norma C - Vancouver}

Colares EO. Considerações sobre educação, arte e política: experiências, alternativas e resistências. Conhecer: Debate entre o Público e o Privado [Internet]. 2019 [cited Ago 1, 2019];9(23):124-140.

Available from: https://revistas.uece.br/index.php/revistaconhecer/article/view/1160 